\title{
LETTERS
}

\section{Absence of alcohol withdrawal syndrome in a remote Indigenous community}

Stephen A Margolis, Valmae A Ypinazar, Alan R Clough and Ernest Hunter

To THE EDITOR: Impacts of alcohol consumption on health and wellbeing in remote Indigenous communities are well documented. ${ }^{1}$ In response, governments have applied supply and demand reduction programs, including the "Meeting Challenges, Making Choices" program, which has lowered the rate of serious injury. ${ }^{2}$ Although a pattern of heavy, episodic drinking has been documented, ${ }^{3}$ the nature of physical dependence in relation to acute alcohol withdrawal syndrome ${ }^{4}$ is uncertain. We report the results of sudden, temporary removal of alcohol in a small Indigenous community.

In a remote Queensland Indigenous community (population, 1021) with one licensed premises, patterns of extreme drinking (30 standard drinks per session) are commonly seen around paydays. In 2008, the Queensland Government withdrew the sole liquor trading licence with 72 hours' notice because of a breach of licensing laws. The licence was subsequently renewed after several months. During this time, there was no significant access to alternative (illegal) sources of alcohol within the community, as the prohibition against bringing alcohol into the community (initiated in 2003) was strictly enforced by police.

Health services in this community comprised a primary health care centre (PHCC) with Queensland Health resident nursing staff, Royal Flying Doctor Service medical staff on weekdays (the principal doctor was SAM), and visiting specialists provided by both organisations, including a psychiatrist (EH). When the closure was being arranged,
Queensland Government authorities requested that these health providers establish a process to treat any patients who developed acute alcohol withdrawal syndrome; this was monitored by SA M.

Four weeks after the sudden cessation of alcohol availability, PHCC staff did not notice any outmigration of regular drinkers, and no patients presented with acute alcohol withdrawal syndrome. These findings are consistent with the anecdotal experience of $\mathrm{EH}$, who has not encountered any cases of withdrawal delirium in this community over the past 16 years. By contrast, in recent years E H has observed several cases of withdrawal symptoms from cannabis use in this community, as seen previously in remote Northern Territory Indigenous communities. ${ }^{5}$

Our results suggest that people can develop physiological or psychological tolerance for heavy episodic drinking, which may be a function of adaptation to the intermittent nature of financial resources. This finding removes a potential health-related impediment preventing governments from considering sudden cessation of legal alcohol supply in these or similar environments.

Stephen A Margolis, Head of Research, ${ }^{1}$ and Associate Professor ${ }^{2}$

Valmae A Ypinazar, Adjunct Senior Research Fellow ${ }^{2}$

Alan R Clough, Associate Professor ${ }^{2}$

Ernest Hunter, Regional Psychiatrist ${ }^{3}$

1 Royal Flying Doctor Service, Cairns, QLD.

2 James Cook University, Cairns, QLD.

3 Queensland Health, Cairns, QLD.

stephen_margolis@jcu.edu.au

1 d'Abbs P, Togni S. Liquor licensing and community action in regional and remote Australia: a review of recent initiatives. Aust N Z J Public Health 2000; 24: 45-53.

2 Margolis SA, Ypinazar VA, Muller R. The impact of supply reduction through alcohol management plans on serious injury in remote Indigenous communities in remote Australia: a ten-year analysis using data from the Royal Flying Doctor Service. Alcohol Alcohol 2008; 43: 104-110.
3 Saggers S, Gray D. Dealing with alcohol: Indigenous usage in Australia, New Zealand and Canada. Melbourne: Cambridge University Press, 1998.

4 Medline Plus Medical Encyclopedia. Alcoholism. Bethesda, Md: US National Library of Medicine; 2008; 5 May: http://www.nlm.nih.gov/medlineplus/ ency/article/000944.htm (accessed May 2008).

5 Lee KS, Clough AR, Conigrave KM. High levels of cannabis use persist in Aboriginal communities in Arnhem Land, Northern Territory [letter]. Med J Aust 2007; 187: 594-595. 